\title{
Erratum to: Analytische Ermittlung der Wicklung-Stator-Kapazität in elektrischen Maschinen zur Vorausberechnung des hochfrequenten Common-Mode-Stroms
}

\author{
J. O. Stockbrügger, B. Ponick
}

Online publiziert am 20. Juli 2021

(c) Der/die Autor(en) 2021

Erratum to: E\&l, Elektrotech. Inf.tech. (2020) 137 (4-5): 196-202 https://doi.org/10.1007/s00502-020-00799-5

Der Artikel Analytische Ermittlung der Wicklung-Stator-Kapazität in elektrischen Maschinen zur Vorausberechnung des hochfrequenten Common-Mode-Stroms von J. O. Stockbrügger, B. Ponick wurde ursprünglich Online First ohne „Open Access" auf der Internetplattform des Verlags publiziert. Nach der Veröffentlichung in Band 137 Heft 4-5 pp. 196-202 hatten sich die Autoren für eine „Open Access"-Veröffentlichung entschieden. Das Urheberrecht des Artikels wurde deshalb in @ Der/die Autor(en) 2021 geändert.

Dieser Artikel wird unter der Creative Commons Namensnennung 4.0 International Lizenz veröffentlicht, welche die Nutzung, Vervielfältigung, Bearbeitung, Verbreitung und Wiedergabe in jeglichem Medium und Format erlaubt, sofern Sie den/die ursprünglichen Autor(en) und die Quelle ordnungsgemäß nennen, einen Link zur Creative Commons Lizenz beifügen und angeben, ob Änderungen vorgenommen wurden.

Die in diesem Artikel enthaltenen Bilder und sonstiges Drittmaterial unterliegen ebenfalls der genannten Creative Commons Lizenz, sofern sich aus der Abbildungslegende nichts anderes ergibt. Sofern das betreffende Material nicht unter der genannten Creative Commons Lizenz steht und die betreffende Handlung nicht nach gesetz- lichen Vorschriften erlaubt ist, ist für die oben aufgeführten Weiterverwendungen des Materials die Einwilligung des jeweiligen Rechteinhabers einzuholen. Weitere Details zur Lizenz entnehmen Sie bitte der Lizenzinformation auf http://creativecommons.org/licenses/by/4. 0/deed.de. Open access funding enabled and organized by Projekt DEAL.

Hinweis des Verlags Der Verlag bleibt in Hinblick auf geografische Zuordnungen und Gebietsbezeichnungen in veröffentlichten Karten und Institutsadressen neutral.

Open Access Dieser Artikel wird unter der Creative Commons Namensnennung 4.0 International Lizenz veröffentlicht, welche die Nutzung, Vervielfältigung, Bearbeitung, Verbreitung und Wiedergabe in jeglichem Medium und Format erlaubt, sofern Sie den/die ursprünglichen Autor(en) und die Quelle ordnungsgemäß nennen, einen Link zur Creative Commons Lizenz beifügen und angeben, ob Änderungen vorgenommen wurden. Die in diesem Artikel enthaltenen Bilder und sonstiges Drittmaterial unterliegen ebenfalls der genannten Creative Commons Lizenz, sofern sich aus der Abbildungslegende nichts anderes ergibt. Sofern das betreffende Material nicht unter der genannten Creative Commons Lizenz steht und die betreffende Handlung nicht nach gesetzlichen Vorschriften erlaubt ist, ist für die oben aufgeführten Weiterverwendungen des Materials die Einwilligung des jeweiligen Rechteinhabers einzuholen. Weitere Details zur Lizenz entnehmen Sie bitte der Lizenzinformation auf http://creativecommons.org/licenses/by/4.0/deed.de.
Der Originalartikel ist online unter https://doi.org/10.1007/s00502-020-00799-5 zu finden.

Stockbrügger, Jan Ole, Institut für Antriebssysteme und Leistungselektronik, Leibniz Universität Hannover, Hannover, Deutschland

(E-Mail: ole.stockbruegger@ial.uni-hannover.de); Ponick, Bernd, Institut für Antriebssysteme und Leistungselektronik, Leibniz Universität Hannover, Hannover, Deutschland 